memoval of that gland increases the severity of the operation, and there is a deep depression leit under the jaw, which is slightly disfiguring; aud in removing it some of the fibres of the facial nerve which go up to the angle of the mouth are sometimes cut, so that control af that angle of the mouth may be slightly affected. About three years ago it occurred to me that I might turn up the submaxillary salivary gland from below, and clear out the contents of the submaxillary triangle from beneath it, and the gland or glands which lie embedded in the salivary gland, then lay the salivary gland back in its place once more. I did that in three instances and those cases gave me the greatest anxiety. One of the patients is dead, and I think he died from having had his salivary gland left, because, a year after the operation, he came back with a big mass growing from the lower part of the gland almost into the pharynx. And although I made a very large operation for the removal of it he died of recurrence of the disease a few months afterwards. In buth the other cases I have been disappointed at the result from what may be termed a cosmetic point of view; the gland bulges a little, and there is a prominence instead of a depression. I think the patients are safe, because it is some time since I operated on them. I do not recommend you to take this course, for the advantages are not nearly great enough to justify the risk.

You will see that four of the first series of twenty-eight patients died of affection of the glands without recurrence in the mouth. which seems a large number alter removal of the contents of the anterior triangle. But, in two of them, the glandular disease was so extensive that there was rapid recurrence in the neck itself. In the other two unusual events occurred, and I direct your attention to these particularly. In one of the patients, although the primary disease was but a kind of button quite on the border of the tongue, and apparently not going far into the tongue, and although I removed it and the glands on that side successfully so that it never vecurred in the tongue or in the glands on that side, he died of diseased glands on the other side of the neck. And that occurred about a year after the first operations. It grew very capidly. I tried to remove the disease, but it was absolutely inoperable. You must take into account that in a certain number of cases-I cannot give you an idea of the proportion, but I think it must be small - the patient is liable, even with disease limited to one border of the tongue, to affection of the glands on the other side of the neck. And this has. led certain surgeons to recommend-though I do not think it has been done in this country - that the glands on both sides of the neck should be removed in every case of cancer of the tongue. I have not got to that stage yet. I donbt if I shall ever do so. I have removed the glands of the neck on both sides for cancer of the tongue, but not when the tongue cancer was limited to one side. I do not think at the present time circumstances warrant so large an operation as that, and I do not think the patients would submit to it.

The remaining patient died of disease of the glands of the posterior triangle of the neck, and again the question arises, Is it necessary, or desirable, to remove the contents of the posterior triangle of the neck when the contents of the anterior triangle are removed? I reply that experience has not taught me that this is neceseary in the ordinary cases. That patient was the first person on whom I performed this operation of clearing out the anterior triangle. He had a bad cancer far back in his tongue, implicating the anterior half arch of the palate, and with that a great cancerous gland under the mastoid muscle, in the parotid region; and $I$ performed a large operation on the tongue and glands at one sitting; I fully expected that in a few months he would have cecurrence of the disease. But to my great surprise he remained well for a year and a half, when he came to show me an enlargement of the glands in the posterior triangle, which he had recently discovered. I attempted to remove them. but they were matted in with nerves and vessels, and it was impossible. I made use of that experience in the case which I related at the beginning of the lecture. There was a large mass breaking down at the angle of the jaw beneath the sterno-mastoid muscle; I therefore cleared out the contents of the posterior triangle. where I found absolutely malignant glands. I think where the disease of the glands is only slight and not adherent, and where they are not badly diseased-in the parotid region you need not remove the contents of the posterior triangle; but if there is severe glandular disease in the parotid region, and beneath the sterno-mastoid, I feel sure you should not be content with removal of the contents of the anterior triangle, but should remove also the contents of the posterior triangle down to the brachial plexus:
I have, naturally, been speaking of disease on only one side of the tongue. If the disease is in the middle line, as it sometimes is, or if it has spread from one side to the other; I am sorry to say you will have to take your courage into your hands, and remove the contents of the triangle on both sides of the neck. I have done so on several occasions, and the patients have made very good recoveries. That is an absolnte necessity if you want to save your patient from recurrence and death from the disease.

And now let me finally say that I am only giving you what I believe to be the best advice, on my experience, up to this time. It is possible I may have to modify my opinions on some of these points, but $I$ am not likely to modify them in the direction of making a smaller operation than I have demonstrated to-day. I advise you, in every case of cancer of the tongue, even in the very earliest period, to recommend your patient most atrongly to have not only the disease of the tongue removed, but if the disease is on one side to have the anterior triangle completely dissected out, and if the disease of the tongue is in the middle line to have the contents of both triangles taken out.

REFERANCE.

\section{ON THE THALAMUS.*}

Bx GUSTAV MANN, M.D.Edin., B.Sc.Oxon., Oxford.

For some years I have been teaching that the central nervous system may be divided into two regions-one lying in front and the other lying behind the plane of the posterior commissure. The anterior or cephalic portion is the thalamus, while the posterior or caudal segment forms the cord. The central nervous system consists therefore, according to my view, of a thalamic and a post-thalarnic division.

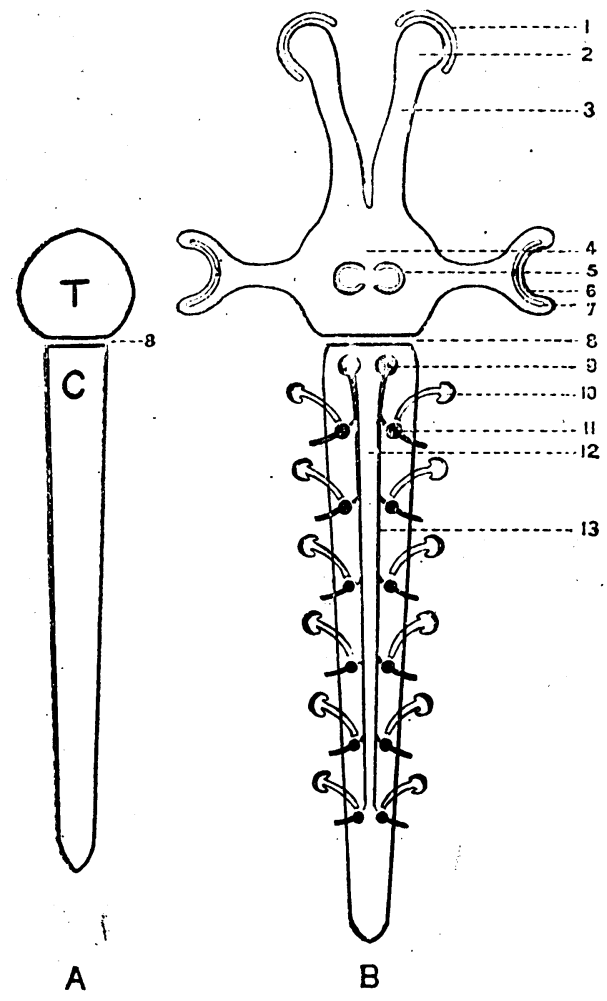

Fig. 1 .

A. -The central nervous system, consisting of a thalamic, $T$, and a post-thalamic, $C$, portion. The plane of the posterior commissure is indicated by 8

B. - - The olfactory mucous membrane; 2 , the olfactory bulb; 3 , the olfactory tract ; 4 , thalamus ; 5 , the two pineal eyes ; 6 , the optic cup ; 7 , the layer of rods and cones; 8 , the plane of the posterior commissure: 9, the red nucleus; 10, a spinal ganglion; 11,8 motor nucleus; r2, cord ; r3, the rubrospinal tract. (For sim-
plicity's sake decussations have not been represented.)

* Res. 3 in the Bection of Anatomy at the annual meeting of the British Medical Association, Oxford, July, rgo4. 
The thalamus gives rise to the corpus striatum, comprising the caudate, lenticular and amygdaloid nuclei ; the claustrum, and the cerebral hemispheres, while the post-thalamus or cord includes the midbrain or corpora quadrigemina; the rhombencephalon including the cerebellum, pons and medulla, and the spinal cord.

In Fig. I, $A$, the thalamus, $\mathbf{T}$, and the cord, $\mathbf{C}$, are separated by the plane of the posterior commissure, 8 .

While the cord is built up of segments, each of which possesses from the very commencement, first]y, sensory nuclei developed in connexion with the spinal and the sympathetic ganglia, and, secondly, motor nuclei developed partly in direct connexion with the axons of cells situated in the spinal and the sympathetic ganglia, and partly in relation to the sensory nuclei inside the cord, we find in the thalamus originally only sensory nuclei. As the function of all afferent (sensory) nerves is to produce movement, it will be seen that the thalamus must either become connected up with motor cells of the cord or develop a motor mechanism of its own. Anatomy and physiology teach us that the thalamns at first was content with employing the motor cells of the cord, but that later it developed its own motor mechanism.

Three distinct stages may be traced in the evolution of the thalamus

The primitive, as distinct from the evolved, thalamus contains centres developed only in connexion with the chemical sense of smell and the physical sense of sight, while the cord arises originally in response to tactile or mechanical stimulation. The thalamus reacts thus to quick vibrations, while the cord responds to slow vibrations, and it is curious that the motor nuclei should first appear in relation to such slow stimuli as are called forth by mechanical disturbances of the eighth nerve, and of the various kinds of touch corpuscles met with in the skin, in muscles, tendons, joints, and viscera.

I believe that pain plays no part in the evolution of the nervous system, and that the capacity of reacting to chemical stimuli has been acquired by the cord only secondarily, as, for example, in the sense of taste.

If from one point of view the nervous system is divisible into a thalamic and a post-thalamic region, it is from another standpoint also divisible into a peripheral and a central portion. In vertebrates, all sensory cells, with the exception of those subserving the sense of smell, are removed from the surface of the body, and are aggregated, except in the sense of sight, into special ganglionic masses-namely, the spinal and sympathetic ganglia. When we study the development of the two latter we find that they form at one time the edges of the medullary plate, which is only what one would expect, because when the medullary plate is converted into a deep groove the edges of the canal will be those portions which remain longest in direct communication with the environment. While, now, in the post-thalamic nervous system the sensory edge of the medullary groove soon separates off from the neural canal proper, and gets to lie along the dorsum of the neural cana], between the latter and the skin, we find in the thalamic region quite a different arrangement.

The sensory cells, which ultimately will subserve smell (see Fig. I, B, I), never form part of the medullary groove, but lie at its anterior end, and they never sever their connexion with the surface of the body. This fact, probably coupled with their inability to form long-axis cylinders, has led to the thalamus retaining from the very first its connexion with the olfactory skin area. Thus, a communication with the thalamus is brought about by the latter growing apparently outwards towards the olfactory region, and giving rise thereby to what in the adult brain is known as the olfactory bulbs and the olfactory tracts (see Fig. I, B, 2, 3).

In the case of sight, the sensory cells lie partly along the edge of the medullary groove, and are brought, through the conversion of the groove into the thalamic canal, into a dorsal position, developing later into the two bilateral pineal eyes, as is well seen in the early stages of development in fishes and amphibians (see Fig. $1, B, 5$ ).*

It would therefore seem that the very rapid vibrations caused by smell and sight cannot be propagated over long distances. That also in the fully-formed retina of vertebrates the rods and cones lie in reality on the surface of the body is shown by the accompanying diagram (Fig. 2) of a nearly

\footnotetext{
* In addition to the pineal eyes, which now have no function, there are developed from the thalamus the two lateral eyes. What is so interesting is the fact that, as in the case of the sense of smell, so here a portion of the thalamus grows out with the true, light-perceiving cells-namely, the
} rods and cones (see Fig. $\mathbf{r}, \mathbf{B}, 6$ ). completed, hypotheticaily double-layered neural canal, and, budding out from the latter, an optic stalk terminating in an invaginated optic vesicle. The non-invaginated part of the optic cup forms the retinal pigment layer, while the invaginated portion represents the retina.

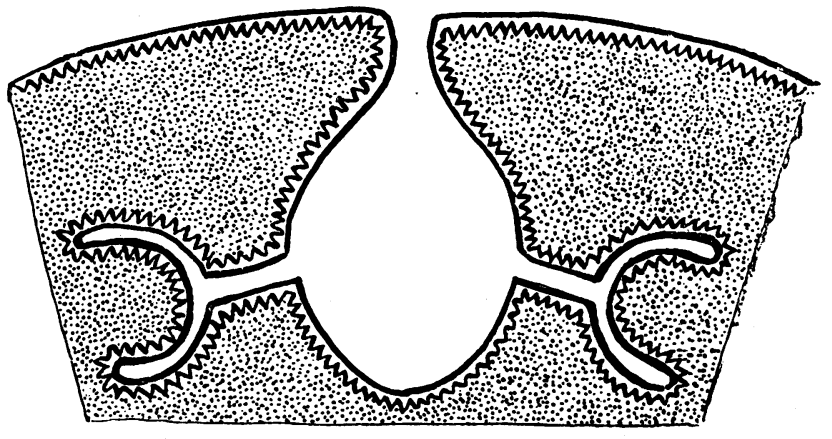

Fig. 2.

As low down as the petromyzon, the sensory nuclei and tracts developed in connexion with the sense of smell are the olfactory bulbs, the taeniae thalami, the ganglia habenulae with their two subdivisions, the fasciculi retroflexi of Meynert, and the interpeduncular ganglia of v. Gudden which latter send fibres to the tegmental ganglia situated immediately behind the midbrain. In animals with a cerebrum we find in addition the fornix, developed in connexion with the sense of smell, going to the ventro-lateral portion of the mesial nucleus of the corpora mammillaria.

The sense of smell is originally in all animals the most, essential; without it none of the lower vertebrates are able to find food, and in those animals, such as man, in which the sense of sight has usurped the place which once was occupied by smell, there is evidence, as Professor Flechsig has told me, of the olfactory sense-organs being more strongly developed in the fetus than at birth. How essential the smell is to the: rabbit was brought home to me by the following experiments: Engaged in making a systematic investigation of atrophic changes induced in the thalamus by removal of various. afferent tracts in newly-born animals according to v. Gudden's method, I also removed one or both olfactory bulbs. Whileall the rabbits with only one bulb removed made a speedyr recovery, none of those survived in which both bulbs hadi been removed. My experience bears out that of $\nabla$. Gudden, when he experimented on newly-born animals. I had hopeds to be more successful by placing the animals periodically against the teats, but with no better result. I thought the filth nerve and the nerve of taste not sufficiently educated during the first few days to respond sufficiently to the sense: of touch and taste; I therefore waited eight, ten, fifteen, and twenty days after birth. After the animals could see and could run about I tried to train their eyes by giving the food. always at definite times and letting the animals see the food first, but again I failed. Then I hoped that if an animal could not find its food by sight alone, as long as it was kept by itself, that it might do so by being taught to watch other animals of its own age feed, and therefore two rabbits had to. watch others eat on each of seven successive days before they were given food themselves. Again I failed in keeping the animals alive after removing both olfactory bulbs. It appears then, that rabbits are as dependent on their sense of smell as are the smell-hunting fishes to which Steiner first drew attention.

As a successful removal of both olfactory bulbs would throw' much light on the thalamus I shall repeat the experiments, using artificial feeding, and also changing the breed of rabhits.

The sense of sight is comparatively a much simpler sense and of much less importance to the rabbit, for if both eyes be enucleated on the second day after birth it soon learns to. educate its senses of touch and hearing to an enormous. extent. The increase in the sensitiveness of the whiskers is particularly noticeable, for while a rabbit which can see takes little or no notice if the whiskers are touched with a straw, a blind rabbit will jump away forcibly under the same conditions. In this respect rabbits resemble the nocturnal rats.

While the tracts of the olfactory sense are complicated, those of sight are comparatively simple. The thalamic 
portion of the retina sends its fibres to the anterior corpora quadrigemina, the external geniculate bodies, and to the posterior portions of the thalamus. In the rabbit the anterior corpora quadrigemina obtain their maximal development, while in the marmoset monkey the pulvinar and the aexternal geniculate bodies are most developed. Finally, $: a$ tract between the retina and the corpora mammillariathe transverse peduncular tract of $v$. Gudden-is the analogue - of the olfactory mammillary tract above referred to.

The second stage in the evolution of the thalamus took place when amongst our remote ancestors all-powerful variation first produced a type in which a special area was set :apart for the mutual interaction of the senses of smell, of sight, and of touch. While during the first stage the eense of smell played through the ganglion habenulae on the sense - of sight, and perhaps also directly on the motor cells of the red nueleus situated in the most anterior part of the cord (see Fig. I, B, 9), and while the thalamic retina certainly - controlled body movements through the red nucleus, there -existed as yet no sensory nucleus in the thalamus for the reception of tactile impressions. but then there arose two - distinct centres-one, probably the older one. situated quite anteriorly, called the anterior tubercle, or, by Ramon y Cajal, the dorsal nucleus; and, secondly, a ventral nucleus, which may again be divided into at least a mesial and a lateral iportion.

Three distinct tracts have been described as passing from the spinal cord to the thalamus: First, the spinorthalamic tract of Horsley, Boyce, and Edinger, the cells of which are said to be situated in the cord, and the axis aylinders of which, aiter decuseating, are said to occupy a wentro-lateral position in the cord and medulla, and then to run forwarde, to terminate in the lateral portion $\rightarrow$ the ventral nucleus; this bundle I do not know personally; secondly, the fillet coming from the cuneate and, to a slight extent, from the gracile nuclei, and termimating in the anterior reaches of the mesial portion of the ventral nucleus; and, thirdly, the bulbo-mammillary tract of Wallenberg, coming from the region of the gracile nucleus and going to the mammillary bodies. From the corpora mammilJaria, a new tract arises-namely, v. Gudden's tegmental tract, the collaterals of which are aggregated to form Vicq d'Azyr's koundle, destined for the anterior tubercle of the thalamus, -and partly for the anterior portions of the middle nucleus.

Tracts, which arise in connexion with the cranial nerves. particularly the trigeminus, are the homologues of the spinal -or mesial fillet, and terminate likewise in the ventral nucleus of the thalamus.

During the third stage of evolution the thalamus developed iits own motor mechanism by giving rise, first, to the cornus cstriatum, consisting of the Jenticular and caudate nuclei, and then to the cerebrum. With the development of these estructures goes hand in hand a reciprocal development of the - original thalamus, inasmuch as the original nuclei send fibres to the corpus striatum and to the cerebrum, and also receive fibres from these regions. The exact delimitation - of the nuclei, depending primarily on the peripheral sense - organs and arising primarily in connexion with the corpus istriatum and the cerebrum, is the research $I$ have in hand.

From what has been said above it will be seen that during no part of its existence was the thalamus connected only with the visual apparatus, and therefore it is best not to use the expression "optic" thalamus.

In a mammalian brain fixed in situ by the injection of so per cent. formalin in 0.75 per cent. sodium chloride solution, the thalamus appears as two oblong masses, which meet one another in the middle line at almost a right angle. For descriptive purposes it is convenient to divide each thalamus into eighteen segments according to the following plan (Fig. 3).

The thalamus is divided naturally into a dorsal and into a 'ventral portion by the falciform nucleus of Ramón y Cajal. 'This nucleus corresponds to Nissl's winglike projection of his " "nucleus of the middle line," the latter in reality consisting of two portions-namely, the central grey matter and the falciform nucleus proper. This division into a dorsal and a "ventral part is especially well marked in the middle regions -of the thalamus.

The dorsal half of each thalamic half may again be redivided for descriptive purposes into a dorsal and a ventral area. but - this division is not indicated in Fig. 3. The surface lonking towards the middle line, following a suggestion of Professor Gotch, I have called the "ventricular" third, and the lateral arpect of the thalamus the "lateral". third; between these two thirds is the "subventricular" third, which term is preferable to the term "central." The central portion of the thalamus lies between its right and left halves in the middle line, and corresponds to the central grey matter and to the ganglion habenulae (see later).

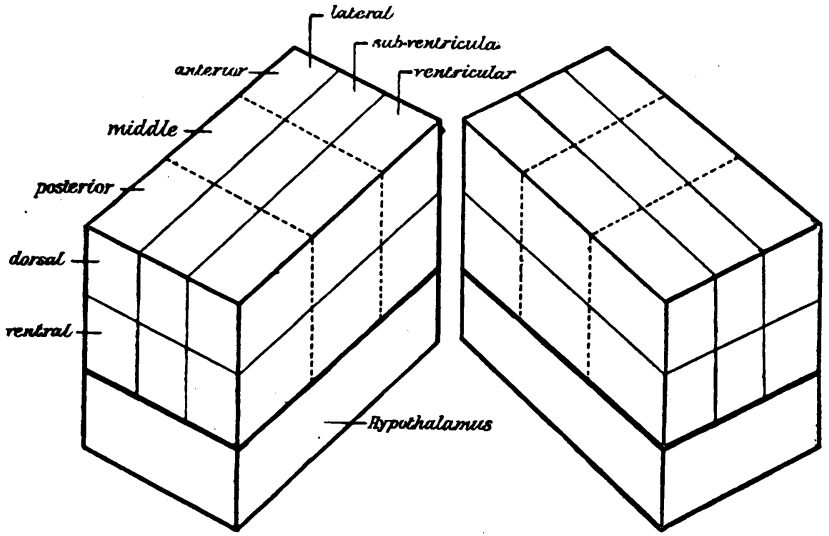

Fig. 3.-Representing the right and left halves of the thalamus resting on the hypothalamus.

The anterior surface of the thalamus is partly also ventricular throughout the antero-ventricular, subventricular, and lateral thirds ; but with the term antero-subventricular I mean to express the middle third of the anterior reaches of the thalamus.

The hypothalamus includes all structures lying beneath the ventral nucleus, in which the fillet terminates, with the exception of the external and internal geniculate bodies, which, because of their enormous development in the higher vertebrates, have come to lie partially in the hypothalamic plane. The hypothalamus is not dealt with here.

The relation of the thalamus to the other parts of the brain in the marmoset monkey is shown by Fig. 4, which represents a horizontal section passing through the posterior commissure. The thalamus, Th, is surrounded by the following parts: (1) Frontal lobe of cerebrum, (2) genu of corpus callosum, (3) lateral ventricle anterior horn, (4) head of caudate nucleus, (5) anterior genu of internal capsule, (6) septum lucidum, (7) claustrum, (8) fornix. (9) Sylvian fissure, (10) stria cornea or taenia gemicircularis, (I1) taenia thalami, (12) central grey matter, (13) lenticular nucleus, (14) posterior genu of internal capsule, (15) internal lamina of thalamus, (16) fasciculus retroflexus of Meypert, (17) ventral portion of pulvinar, (18) posterior commissure, (19) stria cornea, (20) fimbria, (21) tail of caudate nucleue, (22) fascia dentata, (23) anterior corpora quadrigemina, (24) hippocampus major or cornu ammonis, (25) posterior horn of lateral ventricle, (26) posterior corpora quadrigemina, (27) cerebellum. (28) occipital lobe of cerebrum.

The minute structure of the thalamus corresponding to Fig. 4 is given in the diagram (Fig. 13 ). In the figures 5 to 17 are represented successive horizontal planes through the thalamus of the marmoset monkey, an animal which Sir Victor Horsley was kind enough to suggest to me as being probably especially suitable for the purpose of investigating the thalamus.

Its thalamus is composed of the following nuclei :

I. The anterior nucleus (No, $1, a, b$ in Figs. 5 to 13 ).-It lies dorsally in the subventricular zone, and is composed of two parts, namely, a large-celled dorsal ventricular $(I, a)$ and a small-celled, ventral and subventricular part $(1, b)$. The portion I, a corresponds to Nissl's anterior dorsal nucleus and to v. Monakow's ant.-c. Ramón y Cajal homologizes his "angular nucleus" with Nissl's lateral anterior nucleus, but Ramón y Cajal's nucleus seems to correspond to my anterior nucleus I, $a$. The portion $\mathrm{I}, b$ corresponds to Nissl's anterior ventral nucleus and to v. Monakow's ant.-a. or Ramón y Cajal's dorsal nucleus. The anterior nucleus receives its impulses from Vicq d'Azyr's bundle.

2. The ventricular nucleus (No. 2 in Figs. 5 to 14 ).- - It lies dorsally in the ventricular zone, and extends more or less into the subventricular zone according to the level of the transverse plane under examination. On its subventricular side it is bounded by the internal medullary lamina, No. II (Figs. 7 to 13 ); on its ventricular side it is in contact with the central grey matter, No. 12. Within certain reaches it develops a distinct intranuclear lamina, No. 13 (Fig. \&), which 
divides it into a ventricular portion, No. $2, a$, and a subventricular part, No. 2, $b$. Both the ventricular and the subventricular subnuclei are redivided into at least one anterior and one posterior division. On its anterior dorsal surface it

centre corresponds to the posterior nucleus of Nissl's mesial-posterior nucleus and to $\mathrm{v}$. Monakow's med. $b$. If the large-celled nucleus, 2, $c$, belongs to the centre of Lnys, we are dealing here again, as throughout the remainder

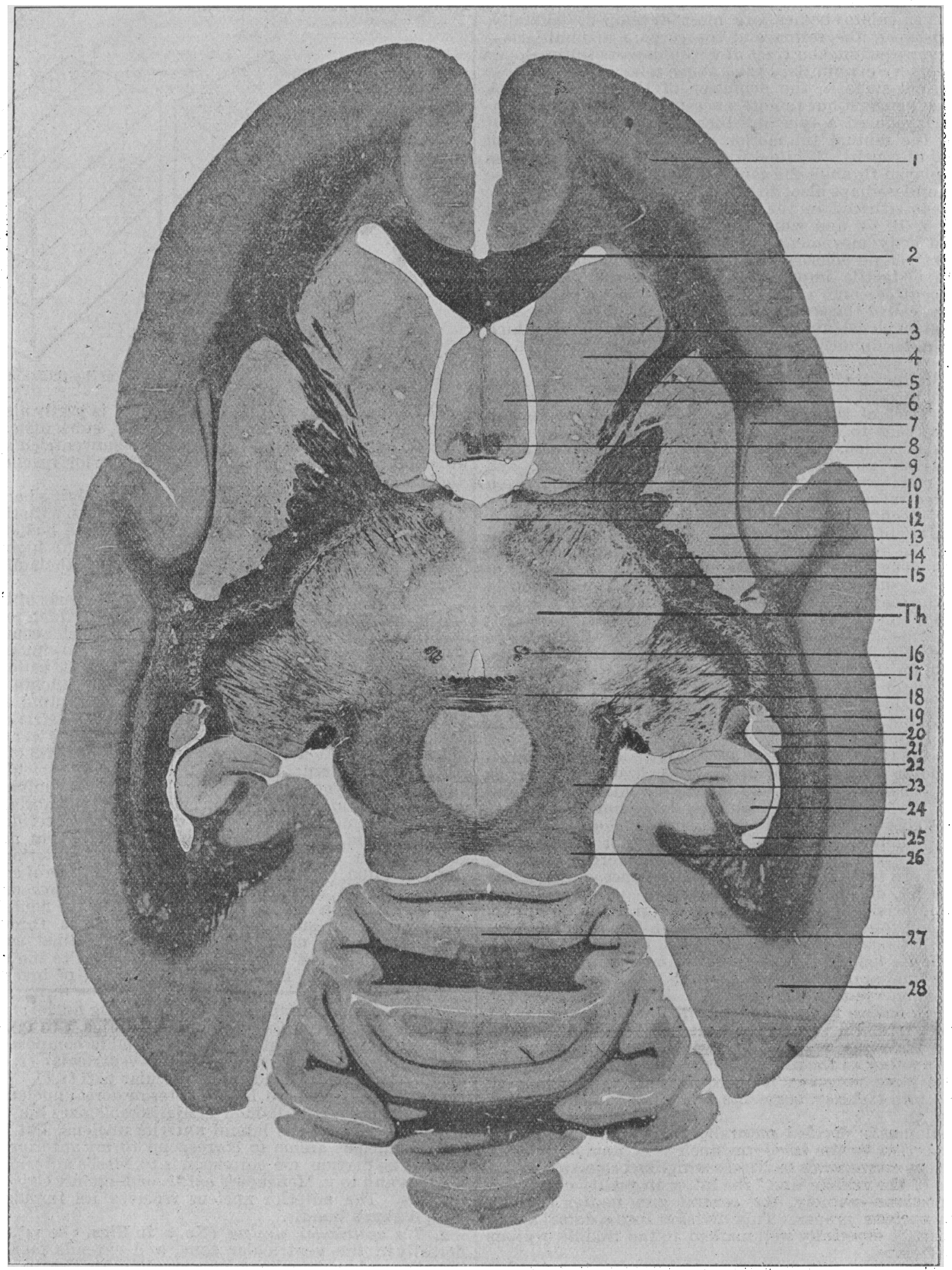

Fig. 4.

passes into "the large-celled nucleus" No. 2, c. This largecelled nucleus, or nucleus magnocellularis of Nisel, lies at the anterior and dorsal end of my No. 2, b, which is known generally as "the centre of Luys (centre median)." This. of the thalamus, with a small-celled receiving, and: a largecelled emitting, subnucleus in each thalamic nucleus. The ventricular portion of the ventricular nucleus, No. $2, a$, corresponds to Nisel's mesial posterior nucleus and to v. Monakaw's 

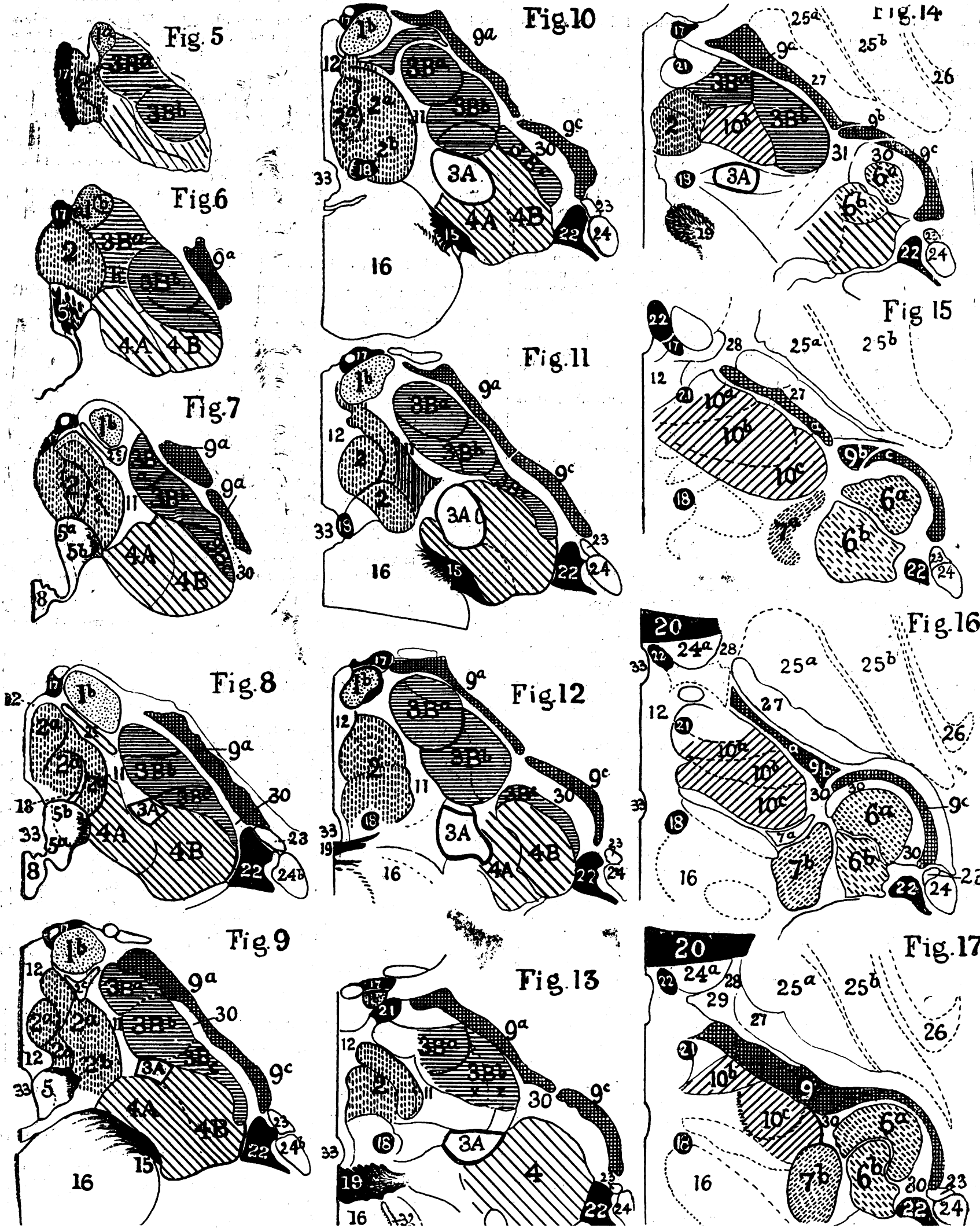

33) 24a $28 i$
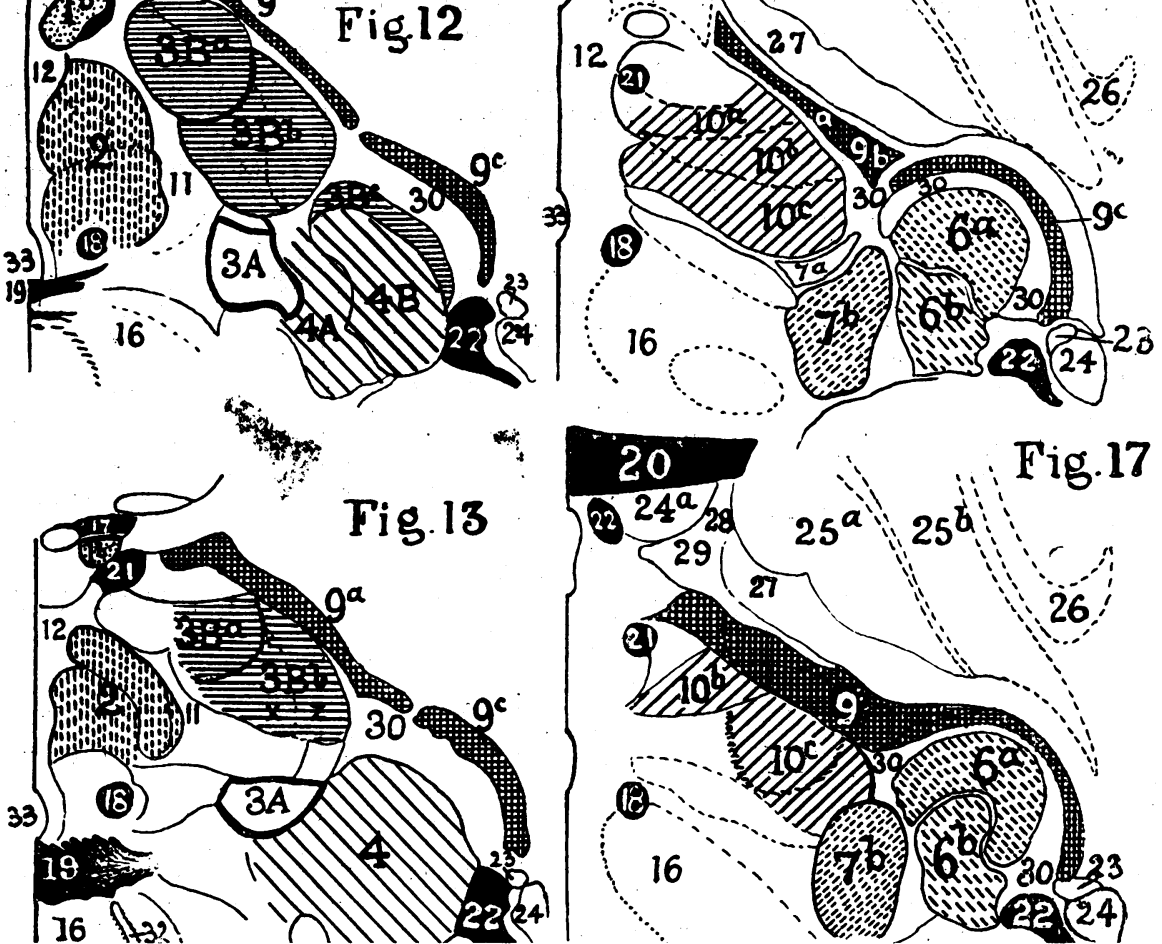

Tigs. 5 to 7 - Sul No. $1, a, b$, the anterior nucleus; 2 , ventricular nucleus; 3 . la reral nucleus: 4 , posterior nucleus; 5 , ganglion habenulae; 6 , external geniculate body ; 7, internal geniculate body; 8, pineal body; 9, relicular nuclei, A, tzctlle (?) portion; B, auditory portion; C, optic portion; D, dorsal

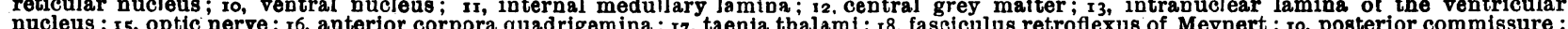
2o anterior, commissure; Vicq d'Azr's bunde: 20, 6, putamon); 26 . claustru m ; 27, internal capsule ; 29 , anterior peduncles of thalamus; 29. Forel's lenticular bundle; 30 , external medullary lamina; 3r, auditory radiation forming part of external medullary lamina; 32 , mesencephalio root of fifth nerve; 33 , third ventricle. 
med. $a$. It has many finer subdivisions, which I have not as get fully worked gut.

3. The lateral nucleus (No. 3, Figs. 5 to 14 ).-It is situated for the greater part in the lateral zone, but it extends also into the subventricular zone. Its subventricular portion, No. i A, is bounded by the internal medullary lamina, No. II, and corresponds to "the semilunar nucleus of Flechsig" which lies, therefore, mesially to the lateral portion of the lateral nucleus, No. $3 \mathrm{~B}$, and in front of the pulvinar, No. 4. The lateral nuclens proper, No. 3 B (Figs. 5 to 16 ), is divisible into a lateral anterior, $3 \mathrm{~B} a$, and a lateral middle, $3 \mathrm{~B} b$, and $a$ luteral posterior, $3 \mathrm{~B} c$, part. It corresponds to Nissl's lateral anterior and lateral posterior portions and to v. Monakow's lat. $a$ and lat. $b$. Anteriorly the lateral nucleus extends almost as far forwards as does the anterior nucleus laterally it is separated from the reticular layer, No. 9, by the external medullary lamina, No. 30 . The middle portion of the lateral nucleus shows usually a well-marked division into a lateral, No. $3 \mathrm{~B} b, z$, and a subventricular region, $3 \mathrm{~B} b, x$ (see Figs. 11 to 13).

As far as it is possible to tell by histological methods No. 3 B consists of a distinct dorsal and a distinct ventra portion; the former $3 \mathrm{Ba}$ is seen in Figs. 5 to 12 , while the ventral division is seen in Figs. 13 to 14 . These divisions, not being quite definitely established, have been numbered in the same way.

4. The posterior nucleus (No. 4 in Figs. 5 to 14).-It consist of a more mesial portion, No. $4 \mathrm{~A}$, on the ventricular side and a lateral division, No. 4 B. The mesial portion abuts in the more ventral regions on the optic nerve, No. 15, which separates it from the anterior corpora quadrigemina, No. 16. The lateral division is the pulvinar proper and is much more developed in the monkey than in the rabbit.

5. The ganglion habenulae (No. 5 in Figs. 6 to 9).-This ganglion may be called, with Edinger, the epithalamns. It is not included in the schematic figure of the thalamus, Fig. 3 . In all animals from the frog to man it runs parallel to the middle line from before backwards. It is composed of small-celled ventricular, No, $5 a$, and a large-celled lateral subventricular part, No. 5 b. It receives its impressions from the taenia thalami, No. 17, and sends its impulses by the fasciculus retroflexus of Meynert, No. 18, to the interpedunculary ganglion of v. Gudden. It is comparatively feebly developed in the monkey while it is large in the rabbit.

6. The external geniculate body (No. 6, Figs, 14 to 20)-It is composed of two very distinct subnuclei, namely, a dorsal, No. $6 a$, and a ventral one, No. $6 b$. It receives its impressions through the optic tract.

7. The internal geniculate body (No.7, Figs. 15 to 17). - It may consist of two parts, namely, an anterior portion (No. 7a, Fig. 15) and a posterior portion (No. $7 b$, Figs. 16 and 17).

8. The pineal body (No. 8, Figs. 7 and 8).

9. The retinae, not represented in the figures.

10. The reticular nuclei (No. 9, A, B, C, Figs. 6 to 17).-These nuclei are but subnuclei; thus No. $9, a$ is developed in connexion with the external geniculate body subserving sight while No. $9 b$ is developed in connexion with the interna geniculate body subserving hearing. No. $9 c$ is intimately related to the ventral nucleus No. 10, in which the fillet terminates, and in its more dorsal reaches it seems to be developed in connexion with the lateral nucleus, No. 3. The dorsal reticular nucleus of Nissl, Jying between $1, b$ and $3 \mathrm{~B}, a$ in Fig. ro, possesses cells of a motor type and is probably the emitting nucleus of the mesial nucleus, with the exception of the centre of Lays, the emitting nucleus of which is the nucleus magnocellularis of Nissl. Till the exact function of these nuclei has been determined experimentally it is best to put them under a separate heading as I have done here.

All the nuclei enumerated above lie in the dorsal half of the thalamus, while the ventral half contains:

II. The ventral nucleus (No. 10, Figs. 14 to 17).-It shows a distinct division into three zones, $a, b, c$. It receives its stimuli from the fillet arising from the caudate and lenticular nuclei ; from the homologous nuclei developed in connexion with the sensory cranial nuclei, and perhaps from the cord directly. Its exact extent was studied by me in the rabbit by Marchi's method, and is now being investigated by v. Gudden's method.

In the discussion a complete series of sixty accurate drawings of transverse sections of the thalamus of the rabbit were used for elucidating the various points mentioned above Inssmuch as without these figures a description of the nuclei would be of little value to the reader, a full description of the nuclei will be published as soon as the wax models of the thalamic nuclei have been completed. There were also shown the actual specimens of the rabbit series and of the monkey series, reproduced in Figs. 4 to 21 , as well as stereoscopic slides of the rabbit's thalamus. The following experimental work bearing directly on the structure and function of the thalamus has been done in rabbits one to three days old: complete removal of the sacral, the lumbar, and the lumbosacral cords, the cerebellum, the eyes, the middle ear, and one-olfactory bulb. These animals were killed after three months and injected by my picro-corrosive method. The results of: these experiments I hope to be able to publish soon.

A complete historical account, dealing with the fiterature, and particularly with the work of $v$. Monakow, Nissl,; Probst, Prus, Edinger, and his pupils, will be given Pater.

\section{REFERENCF.}

1 S. Ramón y Cajal, Textura del Sistema Nervioso, Tomo il, fig. 604.9904.

Sir Victor Horsley, speaking from the degeneration point. of view, agreed very fully with the morphological conclusions: of Dr. Mann-namely, as to the possibility of dividing the thalamus, according to the original view of Burdach, into doreals and ventral portions. He also agreed that the ventral division, of the external geniculate nucleus had different pallial relations from the dorsal division. Further, he discussed the minutestructure of the ventral division of the thalamus, and showed; that the extremely restricted termination of the fillet axones* as localized by the degeneration method was now amply confirmed by the most recent publication by Ramon y Cajal. Both methods tended to show that the "fillet nucleus" consisted of three parts, a central globular portion to the opposite. (antero-posterior) halves of which semilunar nuclei were. applied. Further, he proposed that morphologieal]y the: plexuses of fibres should not be dwelt upon for subdivision of the thalamus, but that the true morphological point was the. cell, and that neurologists needed for the analysis of function. the most minute description of the nuclear collections of cells.

Professor Gotch thought that the most important side of 3 the thalamus was afferent, and that the efferent was , superadded.

Dr. Warrington first of all referred to Probst's work, and! agreed that the fillet terminates in the thalamus. The? thalamus was, he thought, a great relay centre receiving the. terminations of the nerve fibres from the pallium and the cerebellum.

Dr. MAY said that as illustrating the results of lesions in the thalamus in monkeys, and the symptoms resulting therefrom, the following observations might be recorded: In a large; number of cases there was hemianaesthesia and hemianopsia. of the opposite side of the body, confirming the observations. made by Hughlings Jackson in man in 1874. Moreover, there. was, in about half the cases, a most interesting symptom, which consisted in a deviation of the face and head, so that. the face was directed to the side of the lesion, and the opposite ear was drawn down to the shoulder. In is out of 16 monkeys there was paralysis of the opposite side, due to. implication of the fibres of the pyramidal tract; in 9 there. was definite hemianopsia ; in 8 there was turning of the head, and in 4 the pupils were unequal. In many cases the centrilateral pupil was larger than the pupil on the side ofi the lesion, and nystagmus was occasionally present.

\section{ON THE PATHOLOGY AND TREATMENT OF LEPROSY.*}

By Captain E. R. ROST, I.M S., Resident Medical Officer, General Hospital, Rangeos.

The Preparation of Leprolin.

IN January, 1903, I read a paper at a meeting of this Braneh on the antagonism between micro-organisms, and showed a theory, which I now again place before you, which I called the periodic law of diseases. In August, 1903, while working at the antagonism between micro-organisnus in the direction of the bacillus tuberculosus, I hit on the way of cultivating this bacillus rapidly. The bacillus tuberculosus grows very slowly on glycerinized media, and as this slow rate of growth was fatal to the experiments that were being performed, research was made into a way of cultivating it more

* Read before the Burmah Branch of the British Medical Association. First and second communications in the Indian Medical Gazette for Mas and June, rge4. 